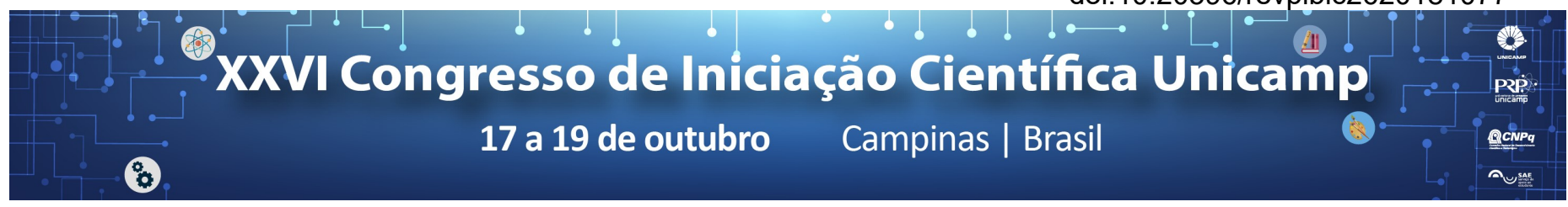

\title{
Produção de pães enriquecidos com compostos bioativos da erva mate (llex paraguariensis)
}

\author{
Natalia G. Murari, Mauricio A. Rostagno, Mariana Corrêa de Souza
}

\begin{abstract}
Resumo
A proposta deste estudo consiste em analisar a produção de alimentos funcionais baseado na utilização de extrato concentrado de erva mate (llex paraguariensis). Neste contexto, analisou-se o enriquecimento de pães com o extrato da erva mate, uma vez que ambos (pão e erva mate) estão presentes no cotidiano alimentar de parte da população mundial. Foi preparado um extrato de mate concentrado que passou pelo processo de liofilização, para que seja possível substituir a farinha de trigo da formulação tradicional em diferentes níveis. A massa e os pães preparados foram analisados a fim de mensurar seus compostos fenólicos e sua capacidade antioxidante. Além disso, ainda será realizada uma análise sensorial dos pães elaborados buscando identificar os níveis máximos de inclusão do extrato de mate na formulação sem afetar sua aceitação, para assim, maximizar seu potencial como alimento funcional.
\end{abstract}

\section{Palavras-chave: \\ Alimentos funcionais, Capacidade antioxidante, Extrato de erva mate.}

\section{Introdução}

Atualmente o chá é uma das bebidas mais consumidas do mundo. Características como agradável aroma e sabor contribuíram para a popularização dessa bebida (SCHIMITZ, et al., 2005). A infusão de erva-mate é uma das bebidas que apresenta quantidades significativas de compostos fenólicos de interesse nutricional, como flavonoides, ácidos fenólicos e taninos (BERTÉ, 2011). As bebidas à base de llex paraguariensis apresentam uma infinidade de propriedades, nutritivas e medicinais, conferindo-lhe um grande potencial de aproveitamento (VIEIRA, 2009). São vários os alimentos funcionais que estão sendo utilizados a fim de enriquecer e desenvolver novos produtos com propriedades funcionais. Esses alimentos não visam apenas satisfazer à fome ou proporcionar os nutrientes necessários, mas também aumentar o bem-estar físico e mental de seus consumidores e auxiliar prevenindo doenças. A tendência atual é de se estudar a adição de fonte de fibras, proteínas, antioxidantes e probióticos, a fim de agregar maior valor nutricional a esses alimentos, principalmente o pão (RAHAIE et al., 2014; MENRAD, 2003). Isto porque, o pão tornou-se um dos principais alimentos em nível mundial e a adição de constituintes com propriedades funcionais como os compostos fenólicos podem ser aplicados no seu enriquecimento, podendo melhorar as características funcionais, tecnológicas e sensoriais (DOMINGOS, 2014).

Para tanto, o objeto de estudo do presente trabalho é analisar a produção de pães funcionais, baseado na utilização de extratos concentrados de chá mate (Ilex paraguariensis) através da substituição da farinha de trigo, em diferentes concentrações.

\section{Resultados e Discussão}

Os resultados prévios (Figura 1), mostram que os compostos fenólicos permaneceram em quantidades consideráveis, mesmo após o pão ter passado pelo processo de cocção, notando então que os compostos não foram degradados mesmo após o processamento térmico. Nota-se também, que ao aumentar as porcentagens de inclusão do extrato na massa do pão, aumenta-se a concentração de fenólicos totais (Figura 1), o que era o esperado.
Além disso, é possível perceber que nos pães assados a quantidade de compostos fenólicos é ainda maior que no pão cru, e isto pode ser justificado pela evaporação da água no momento da cocção, concentrando mais esses compostos.

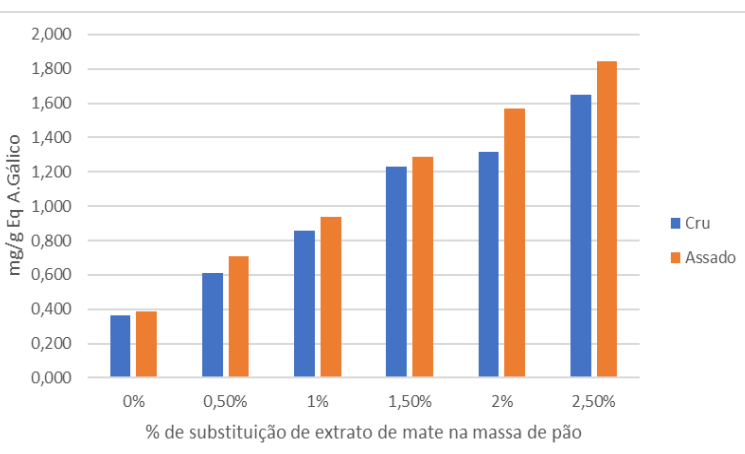

Figura 1. Concentração de fenólicos totais na massa do pão.

\section{Conclusões}

A incorporação do chá mate ao pão, aumenta a concentração de compostos fenólicos e antioxidantes proporcionalmente à sua concentração. Essa é uma forma de enriquecer o pão e torna-lo um alimento funcional. Dessa forma, o extrato de mate tem um enorme potencial para o enriquecimento de pães com os consequentes benefícios à saúde.

\section{Agradecimentos}

Fundação de Amparo à Pesquisa do Estado de São Paulo (FAPESP), 2017/24142-0

BERTÉ, K.A.S. Tecnologia da erva-mate solúvel. Tese (doutorado) Universidade Federal do Paraná, Setor de Tecnologia, Programa de Pósgraduação em Tecnologia de Alimentos, Curitiba, 2011.

DOMINGOS, G. L. Aplicação de Extratos vegetais fontes de compostos fenólicos no processamento de pães de forma. 2014. Disponível em: < http://repositorio.utfpr.edu.br:8080/jspui/bitstream/1/2159/1/MD_PPGTA_M_D omingos $\% 2$ C $\% 20 \% 20$ Glacielly $\% 20 \mathrm{de} \% 20$ Lima_2014.pdf $>$. Acesso em: 24 out 2017.

RAHAIE, S. et al. Recent Developments on New Formulations Based on Nutrient-Dense Ingredients for the Production of Healthy-Functional Bread: A Review. Journal of Food Science and Technology, V.51 n.11, 2014 SCHMITZ, W.; SAITO, A.Y.; ESTEVÃO, D.; SARIDAKIS, H. O. O chá verde e suas ações como quimioprotetor. Semina: Ciências Biológicas e da Saúde, v. 26, n. 2, p. 119-130, 2005 